\title{
Engendering twenty-first century workplace literacy for the hospitality industry: exploring the role of the academic library
}

\author{
Brenda van Wyk ${ }^{1}$ and Lorette Jacobs ${ }^{2}$ \\ bvanwyk@iie.ac.za ORCID: 0000-0003-3898-7042 \\ ejacobl1@unisa.ac.za ORCID: 0000-0001-8081-7739
}

Received: 17 July 2019

Accepted: 22 November 2019

\begin{abstract}
With global competition, sustainable development and economic growth in mind, organisations are under constant pressure to change and stay current. In the knowledge society, where twenty-first century attributes are key, the ability to use information towards continuous learning and evolution in the workplace is imperative. Among other qualities, sound workplace literacy is a necessary attribute that students, as prospective employees, must attain. Student learning must be augmented with relevant experiences to develop a range of literacies related to creativity, innovation, communication, collaboration and the effective use of information in a world where technology evolves rapidly. Higher education needs a better understanding of industry requirements related to the literacies and other attributes expected from graduates entering the market. Exploring industry-related needs, aligning support and library services accordingly and improving inter-departmental collaboration within higher education will better prepare students for the demands in the challenging and fast-changing world of work. This paper reports on a literature review and the findings of a survey on required workplace literacies in a sector of the hospitality and tourism industry. It highlights the importance of more effective collaboration between academics and librarians in supporting the development of workplace literacy. To this aim, a purposively selected target population in a leading South African hotel group was approached. Evidence shows that there is a gap between the level of workplace literacy support offered to students and the actual literacy needs reported by the target group. Based on the findings and extrapolating from recent research, a meta-literacy framework is offered in support of developing twentyfirst century workplace literacies.
\end{abstract}

Keywords: Hospitality and tourism, twenty-first century workplace literacy, academic librarians, embedded librarianship, meta-literacy

\section{Introduction}

Workplace literacy is not a new concept, but one that is presently receiving renewed attention from industry as well as in higher education curricula. While changes in twenty-first century workplace literacy are emerging, the core need is to build, maintain and increase employees' capacity to negotiate complex social, informational and technological working environments. Molopyane and Fourie (2015: 563) postulated that trends in global competition, sustainability and technological developments compel organisations to seek suitably qualified and workplace literate employees.

Within the South African economy, the hospitality and tourism industry is a prominent employer, offering employment to $9.3 \%$ of the South African job market during 2018 and 10.1\% in 2019 (South Africa: Department of Statistics n.d.). Students entering the hospitality and tourism market require a variety of workplace literacy skills and attributes such as interpersonal communication, entrepreneurship and problem-solving skills, analytical competencies, and specific technical skills (Yiu \& Law 2012: 379). Due to the growth in the hospitality and tourism industry, as well as the extent of workplace literacy required of first-time employees, higher education institutions in South Africa are pressured to offer a range of qualifications with curricula designed to produce workplace-ready graduates (Băltescu 2016).

Practical experience, real-life exposure and learning through simulation have become imperative in hospitality and tourism education. Furthermore, with the technological evolution of the Fourth Industrial Revolution (4IR), demands on higher education institutions to offer workplace-based learning opportunities that answer to twenty-first century challenges have increased (Howlett \& Waemusa 2019). Higher education must adapt and expand traditional teaching, learning and

1. Dr Brenda van Wyk is Head of Library and Information Services, Central Academic Team, The Independent Institute of Education, South Africa

2. Dr Lorette Jacobs is Senior Lecturer in the Department of Information Science, University of South Africa 
assessment practices (Alpert, Heaney \& Kuhn 2009: 36). This requirement links closely to the Sustainable Development Goals that aim, inter alia, to support expanded and affordable access to quality technical, vocational and tertiary education (UNESCO 2015). Frick and Kapp (2009) confirm that there is increased pressure on higher education institutions to provide opportunities for the advancement, creation and dissemination of workplace literacy and lifelong learning. Coates and Goedegebuure (2012: 875) described the scenario as "an onslaught of pressure", which calls for a concerted effort of all academic partners of higher education institutions to participate in achieving the desired results.

Researchers (for example, Shumaker 2012, Neerputh 2014) agree that academic libraries and academic librarians must now, more than ever, ensure embeddedness in the curriculum and align themselves with educational pedagogies and technologies to have impact and purpose. Academic partners must collaborate to ensure that workplace professionals are equipped to understand information needs and be able to search, locate, evaluate and apply information within an information and technology intensive workplace context.

\section{Purpose and scope of the research}

Within the above context, this study investigated the nature of workplace literacy required by the hospitality and tourism industry in South Africa within a particular hotel group. It explored the views and needs expressed by the employer related to workplace skills expected from graduates. The literature review explores global trends and reports on current research on the topic. The study concludes by offering a framework for workplace literacies and on how academic librarians can become embedded in the academic process to support their development.

\section{Contextualising workplace literacy}

Workplace literacy generally refers to skills related to the ability to display a characteristic or quality needed by employees in a workplace (Folinsbee 2009, Perez \& Trello 2012). These skills are linked to workplace attributes such as problemsolving, listening, communication, teamwork, leadership and technology application - which form the foundation for workplace literacy. Workplace literacy skills and attributes have evolved and expanded considerably this century to include new technologies and related skills. Workplace literacy refers to how individuals learn and develop the skills and attributes needed to secure, maintain, advance and develop an informed and professional identity in a technology-intensive world. New employees must have the ability to act autonomously, be self-organising, self-motivated, and utilise information and knowledge in creative and innovative ways to create their own work opportunities (Perez \& Trello 2012). The applied attributes of critical thinking, collaboration and creativity are important workplace literacy skills required by workers in the global economy.

Ottonicar, Valentim and Mosconi (2018) posited that the advent of the 4IR, as a rapid and revolutionary process, impacts the world of work which has become increasingly complex and competitive. Farrell (2017) suggested that workplace literacy skills and attributes are required to evolve and adapt in a world where there is a fusion of technologies in the physical, digital, and biological spheres. Workplaces are transforming and are linked to complex networks of technologies, people and practices. Here, additional workplace literacy skills and attributes will be required. As developments associated with artificial intelligence, robotics, the Internet of Things and the Internet of Services are revolutionising work environments, the focus of new workplace literacy will, according to Goedegebuure and Schubert (2017), be on managing fluid and transient work spaces, displaying STEM (science, technology, engineering and maths/numeracy) skills as well as corresponding personal attributes and attitudes. Butler-Adam (2018) further suggested that the development of skills and attributes towards excelling at abstract cognitive analysis, problem-solving, and ethical and moral decision-making are essential attributes needed in today's workplace, as are understanding the interrelatedness between economic, social and political information.

\subsection{Workplace literacy in the hospitality and tourism industry}

Within the context of the hospitality and tourism industry, the scope and variety of workplace skills and required attributes may vary in terms of workplace differences such as technology, systems, managerial practice and philosophy. Ottonicar, Valentim and Mosconi (2018) stated that knowledge of what employers require must be considered in preparing graduates for employment. An earlier study conducted by Saayman and Geldenhuys (2003) suggested that computer, arithmetic, business writing, listening, language and negotiation skills are important in the hospitality and tourism industry. In addition, prospective employees should be able to display ethical attributes and cultural sensitivity. More recently, Ackehurst and Loveder (2015: 11) added that the twenty-first century tourism and hospitality industry requires workplace literacy skills and attributes increasingly related to new technologies and digital skills. Here, digital skills enable employees to use technologies to develop websites, manage social media, e-commerce and e-marketing, all aimed at transforming customer communication. In addition, customer service, business management and entrepreneurial skills are required. 
Students in the tourism and hospitality industry will be required to develop complementary capabilities such as interpersonal skills, civic responsibility and social and cultural understanding (Gilbert 2017). Zwane, du Plessis and Slabbert (2014) proposed that employers in the tourism and hospitality industry seek employees who are flexible, adaptive, proactive and transformable. Tacit skills such as time management, organisational management and multitasking are important in this industry that demands cognitive and problem-solving abilities. Shivoro, Shalyefu and Kadhila (2018) suggested that it is expected of employees in the tourism and hospitality industry to be information literate as information literacy (IL) is seen as the foundation to improve problem-solving skills and grow the ability of individuals to work collaboratively with others. The findings of this study support these statements.

Butler-Adam (2018: 1) affirmed that students in the hospitality and tourism industry will increasingly have to learn how to apply and manage new technologies and that "workplaces will require adaptable people whose jobs are continuously reimagined, enriched and facilitated by technology". Ensuring this adaptability requires employees to possess a range of literacies and skills to know how to find, evaluate and use information and information technologies to adapt to the world around them. Shamim et al. (2017: 8) agreed with this view and explained that, in the hospitality and tourism industry, learning, knowledge and innovation are crucial for successful workplace navigation in the 4IR. The 4IR will affect the hospitality and tourism industry in areas of mass customisation, big data analysis, data security, smart working in an online environment with an ever-changing list of digital and disruptive technologies. Future employees must therefore have the necessary skills to manage their work environment in these changing contexts.

This study aimed to assess the extent of workplace literacy skills required in the hospitality and tourism industry. It explores the role of academic libraries in higher education institutions in supporting workplace literacy required in this industry.

\section{Methodology and data collection}

The study was conducted within an interpretivist paradigm. Within the interpretivist paradigm, researchers believe that reality is socially constructed and that there are many intangible realities. Individuals develop subjective meanings of their experiences and are constantly involved in interpreting their ever-changing worlds (Creswell 2009:8). The main point of interpretivism is that researchers are interested in the ways people interrelate and reason. Applying the principles of interpretivism, a case study design was used as the study relates to an enquiry that investigates a contemporary phenomenon within a real-life context. A case study aims to add to the body of knowledge where existing knowledge is limited. A purposively selected target population in a South African hotel group was surveyed. Following an inductive approach, a questionnaire consisting of open-ended questions was utilised to allow participants to provide detail on their views of workplace literacy skills and attributes.

The three-star hotels in the selected hotel group were targeted. Forty-two online questionnaires were sent to general and training managers in the target group. All ethical protocols were observed. Written permission was obtained from the management of the hotel group and participation was voluntary and anonymous. Participants did not receive any payment, monetary or otherwise. Participants could retract and choose not to participate during any stage of the research. Thirty-nine responses were received, a 93\% response rate.

Key questions asked during the execution of this study included the expectations of participants about the workplace literacy skills and attributes required of entry-level employees, and how higher education institutions can help improve workplace literacy skills that will assist employees to be better prepared for the world of work. Steps proposed by Bezuidenhout and Cronje (2014: 233) were followed in the analysis of data related to the above questions. These steps included preparing and organising the data, developing a coding scheme, testing the coding scheme, coding the data, capturing the data, interpreting the data and reporting on the findings.

\section{Findings}

Through the process of coding participants' feedback on the workplace skills required of first-time employees entering the job market, several skills could be identified. These skills, as well as the percentage of participants mentioning these skills as important, is presented in Table 1.

Based on the summary given in Table 1, it is evident that service orientation is perceived by participants as the most important workplace literacy skill required of entry-level employees. In this context, one respondent mentioned that "a more realistic expectation of the workplace reality will assist new employees to be better adjusted". This statement is in line with the findings linked to the second question about what academic institutions should do to enhance workplace literacy. Here, respondents indicated that technology, information and computer literacies are skills that graduates need to improve. The respondents lamented that retraining of graduates is usually needed and stated that there should be closer collaboration between industry and higher education in closing this gap. There is a general feeling that current curricula do not prepare 
graduates sufficiently for real-life situations or coping with disruptive technologies, which would include virtual and augmented realities which the respondents feel have simulation value.

Table 1 Key workplace literacy skills identified by participants and percentage of participants mentioning the skills

\begin{tabular}{lc}
\hline Key workplace skills identified & $\begin{array}{c}\text { Percentage of participants } \\
\text { mentioning the workplace skill }\end{array}$ \\
\hline Service orientation & $86 \%$ \\
Information security and privacy & $81 \%$ \\
Literacies, information and information technology skills & $81 \%$ \\
Problem solving & $80 \%$ \\
Business communication skills & $76 \%$ \\
Ethical conduct & $75 \%$ \\
Web navigation & $64 \%$ \\
Netiquette & $63 \%$ \\
Self-determined learning & $60 \%$ \\
Networking & $50 \%$ \\
Professional conduct & $40 \%$ \\
Conflict handling & $40 \%$ \\
Health and safety & $20 \%$ \\
\hline
\end{tabular}

The findings of the survey support what Zwane, du Plessis and Slabbert (2014) suggested, that, specifically in the tourism and hospitality industry, the expectation is that exiting students are equipped with basic literacies and knowledge of the industry, where commitment, innovation, and the ability to manage new technologies can contribute towards a productive workplace environment. Based on the study findings, one can further explore the role of higher education institutions and their libraries in developing workplace literacy skills and attributes.

\subsection{Promoting workplace literacy}

According to Kirton and Barham (2005:368), developing workplace skills requires a fresh approach from academic librarians to expanding their roles and functions within the execution of curricula. To achieve the goal of preparing students to succeed in a fluid workplace environment, higher education institutions are required to deploy and coordinate all academic partners. Perez and Trello (2012) referred to the 2009 Global University Network for Innovation (GUNI) report, stressing the central purpose of higher education institutions to be "the explicit facilitator of progressive, reflexive, critical, transformative learning that leads to improved understanding of the need for, and expression of, responsible paradigms for living". Higher education must prepare graduates to be employable in the demanding and ever-evolving world of work. According to Fisk (2017), this preparation includes being able to develop and improve a variety of skills to manage disruptive technologies associated with the 4IR. The findings of this study confirm the statement by Fisk (2017) in that respondents reported that new skills in using fast-changing technologies effectively and responsibly in the hospitality and tourism industry are highly sought after. Clement (2013) reported that sales and marketing are areas in the hospitality and tourism industry where these changes were experienced the most. He referred to the adjustments that were required as "disruptive innovation" (Clement 2013: 64). The term 'disruptive technologies' refers to technologies that will blur the lines between physical, digital and biological spheres. The pace and scale of changes and developments is explained graphically in Figure 1 which summarises these major disruptive technologies, the change they drive, and the emerging opportunities. Chen and Klimoski (2007) emphasised that embracing the 4IR and its challenges, and training to deal with and manage opportunities linked to disruptive technologies are more important than ever.

Shamim et al. (2017: 10) explained that skills required to engage with and manage disruptive technologies require a change in literacy training to expose and empower students to function effectively in highly fluid workplace environments. Abu Mezied (2016) agrees and postulated that curricula should be adapted towards new technologies, where an integration will occur between digital and emerging technologies. In this context, Shamim et al. (2017: 10) emphasised the importance of gaining new knowledge by understanding patterns of information.

The burning question is: are higher education, and specifically academic libraries, keeping track of these revolutionary changes and are IL programmes aligned with these revolutionary requirements? 


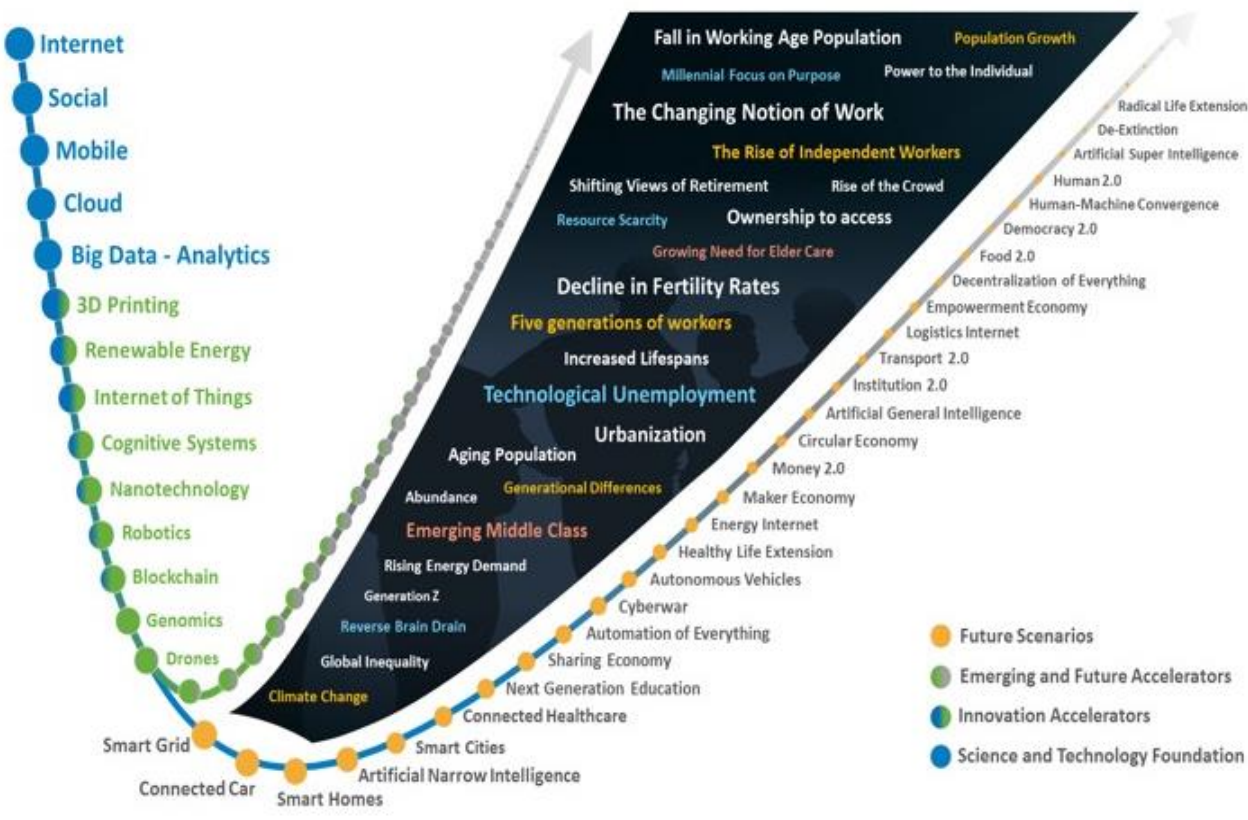

Figure 1 A summary of disruptive technologies (Fisk 2017)

\subsection{Academic libraries as academic partners in developing workplace literacy}

Travis (2011) alluded to the importance and necessity of IL programmes to expand and further promote a range of literacies, including workplace literacy. Earlier, Somerville and Nino (2007: 187) suggested that libraries adopt an "outward approach" and take proactive steps to support academics in the development of much-needed workplace literacy programmes, over and above the traditional IL programmes offered.

Kirton and Barham (2005:366) opined that programmes offered by academic libraries should also focus on sources of information that lie outside the domain of the library and how to find and use these in an ethical manner towards problemsolving, creativity and innovation. It is evident that programmes offered by academic libraries should provide students with knowledge of the broadened scope of information, technology and information use beyond the referencing and plagiarismprevention support traditionally offered.

The question, according to Brown and Malenfant (2017: 3), is how academic librarians should go about assisting in the development of workplace literacy skills and attributes. Lloyd (2011: 250) suggested that a notion of 'practice' be applied. This view focuses on the community (workplace environment) as the context or frame to be applied in the offering of workplace skills programmes. The view is supported by Hoyer (2011: 10) who suggested that programmes offered by academic librarians be created within the context of academic and workplace needs, using the social setting in which the skills will be used. The principle of practice therefore acknowledges the social and cultural dimensions that influence skills required within a particular context (Lloyd 2011: 250). Towards developing programmes to support the development of various workplace literacies, Limberg and Sundin (2006) suggested the use of four approaches:

- The source approach aimed at teaching students to use and evaluate different types of sources available within and outside the library context.

- The behavioural approach which focuses on learning a set of steps to replicate a research process within various subject- or industry-related contexts.

- The process approach which relies on cognitive models and emphasises the nature of information seeking, evaluation and utilisation towards new information sources.

- The communication approach which focuses on social navigation and interaction between users during information seeking, evaluation and utilisation.

With reference to these approaches, Mackey and Jacobson (2011) stressed the importance of expanding programmes offered by academic librarians towards the development of meta-literacies, with IL becoming the foundation for all other literacy skills and attribute development. The meta-literacy framework proposed by the Association of College and Research Libraries (ACRL) (2015) focuses on the development of metacognition, with students needing to understand their roles as information creators and users in the world of work. Meta-literacy promotes critical thinking and collaboration in a digital age 
and provides a more comprehensive framework for skills required for developing and strengthening workplace literacy. Adapted from Mackey and Jacobson (2011) and based on the research by Fisk (2017), a meta-literacy framework that may be considered by academic librarians for providing extended support for developing workplace literacies is presented in Figure 2. This adapted framework has been informed by the ACRL Framework for Information Literacy for Higher Education (ACRL 2015).

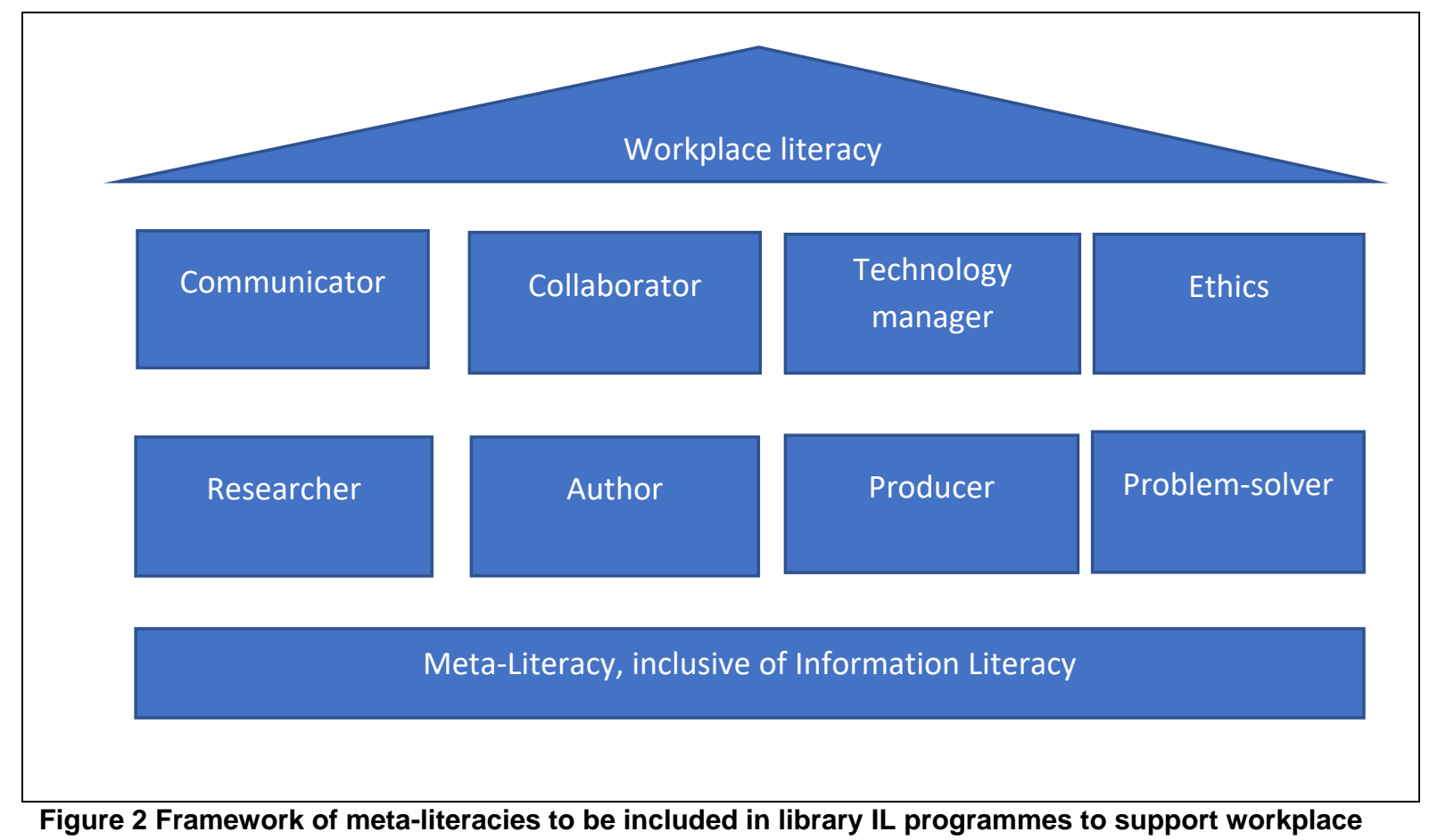
literacy

Aligned to the meta-literacies framework presented above, Table 1 indicated that skills related to information security, information privacy, problem-solving, ethical conduct and web navigation are important. Thus, academic libraries should include detail related to IL (the ability to find and utilise information related to various information sources), technology management, ethics and problem-solving as key focus areas in programmes offered to students within the tourism and hospitality industry.

The meta-literacies framework supports the selection of information resources, the effective creation of search strategies to obtain information that aligns with specific information needs, the evaluation of such information and the use of it in a different context (Kirton \& Barham 2005: 369). Meta-literacies should support students to engage in the production and sharing of information in collaborative face-to-face and online communities. Including meta-literacy skills as part of the programmes offered by academic libraries challenges traditional skills-based approaches to IL by expanding such programmes to recognise related literacy types developing from emerging technologies. As indicated in Figure 2, the framework is founded on strong meta-literacy skills, which support eight frames of literacy skills, each central to developing attributes required in a twenty-first century workplace environment. The eight concepts that anchor the frame (ACRL 2015) are:

- Research as inquiry

- Author of content constructed as original interpretations which is contextual and where information is part of the creation process

- Producer in engaging with various technologies to present information in various contexts such as visual, graphic, sound, digital and virtual reality, augmented reality, etc.

- Problem-solver where information is identified, accessed and utilised in various contexts to solve a variety of realworld problems

- Communicator to share information in an innovative and creative way towards the achievement of a specific goal

- Collaborator as creator of information in a social and educational context

- Technology manager to ensure accessibility and use of information

- Ethics as strategic exploration in the use of information sources in an ethical manner, inclusive of acknowledging privacy and copyright laws 
In today's evolving digital and online world, students as potential employees must not only be able to determine the extent and quality of information needed, but also the format and delivery mode of the information itself. Ackehurst and Loveder (2015) explained the significance of digital skills, among others, in tourism, travel and hospitality due to the advancements and changes that this industry encounters. Having a command of meta-literacies connected to information and technology is of critical importance. Meta-literacy skills should therefore be imparted during a range of workshops offered by academic librarians that focus on searching for information, referencing techniques, navigating the web to find credible, academic information, publishing information online, and plagiarism prevention. Meta-literacies can potentially enable employees to better handle information and convert it into knowledge to create a competitive edge in any work environment.

\section{Discussion}

The literature review for this study revealed a paucity in recent research in South Africa and more in-depth research is required on the current workplace literacy needs as well as the suitability and effectiveness of libraries' literacy programmes for the broader South African academic community. Based on the insights gained from the literature and case study, areas of improvement are suggested for higher education institutions and their libraries to incorporate information literacies for the workplace into existing work readiness programmes.

\subsection{The need for embedded library and information support within the curriculum process}

To offer programmes related to various literacies that can support the development of workplace literacies, Shumaker (2012:3) suggested that librarians become embedded in the academic process. An embedded librarian can be described as a librarian that works closely with academics as part of the academic and research practices of the higher education institution, whether inside or outside of the library environment (Almeida \& Pollack 2017: 123). For academic librarians to become part of the academic process towards the development of workplace literacy skills, librarians need to create opportunities to interact constructively and have meaningful engagement with faculty members as well as members of specific industries. Engagement can be promoted through policy, the attendance of faculty meetings, and direct discussions with management, academics and workplace practitioners.

With a better understanding of the workplace skills needed through such engagements, academic librarians can develop strategies to implement workplace literacy programmes and further collaboration with academics in team-teaching initiatives (Almeida \& Pollack 2017:124). There is a critical need to embed library support in teaching and learning.

Becoming embedded in the curriculum execution process requires a strong, continuous working relationship between the librarian, other support teams and academic teams, which involves sharing the responsibility of curriculum outcomes, inclusive of the development of workplace literacy skills (Bowker \& Villamizar 2017). Ultimately, the goal of higher education is to educate students through the development of their intellectual abilities and to address development needs of society by providing knowledgeable and digitally skilled individuals who can contribute to the labour market. As part of achieving this goal, the embedded librarian should share in the responsibility of outcomes of higher education, including the development of workplace literacy skills and attributes (Bowker \& Villamizar 2017: 60).

\section{Recommendations}

Based on the insights gained, areas of improvement are suggested to incorporate workplace literacies into the existing library programmes. Employability comprises two main aspects: subject or discipline-specific skills, and transferrable skills (Shivoro, Shalyefu \& Kadhila 2018). Both types of skills are important to prepare students for the world of work. Through collaboration with industry and closer working relationships with academics, workplace literacy skills and attributes may be improved to better prepare students for the fluid workplace environment that awaits them in the 4IR.

Learning opportunities and exposure of graduates to the world of work in the hospitality and tourism industry should be augmented with collaborative efforts of both academic and support services such as the academic library. South African higher education institutions have the resources at their disposal but need to make a paradigm shift in deploying these resources to create opportunities where workplace literacy skills of students can be developed and strengthened through all encounters in the academic environment.

\section{Conclusion}

Students need more guidance and support to progress to where they take responsibility for their own learning. The study proposes a continuous approach towards cultivating meta-literate graduates throughout their years of study, with the library as an active partner. This process typically starts with IL training and gradually builds on this foundation towards developing multiple literacies including research skills, communication skills, technology management skills and problem-solving skills. Equipped with these basic skills, employers can further develop workplace specific skills. Partnerships between industry, 
the academic department and the academic library are possibilities that need to be explored to enable higher education institutions to prepare a student for the world of work.

\section{References}

Abu Mezied, A. 2016. What role will education play in the Fourth Industrial Revolution? [Online]. https://www.weforum.org/agenda/2016/01/what-role-will-education-play-in-the-fourth-industrial-revolution/ (9 January 2019).

Ackehurst, M. and Loveder, P. 2015. Building the capabilities of the travel, tourism and hospitality workforce. Paper presented at the AFTA Industry Leaders and Educators Engagement Symposium. February 2015. Sydney, Australia.

Association of College and Research Libraries (ACRL). 2015. Framework for Information Literacy for Higher Education. ACRL: Chicago. [Online]. http://www.ala.org/acrl/sites/ala.org.acrl/files/content/issues/infolit/Framework_ILHE.pdf (2 January 2019).

Almeida, N. and Pollack, J. 2017. In bed with the library: a critical exploration of embedded librarianship at the City University of New York. Communications in Information Literacy, 11(1): 122-146.

Alpert, F., Heaney, G. and Kuhn, K. 2009. Internships in marketing: goals, structures, and assessment: student, company, and academic perspectives. Australasian Marketing Journal, (17): 36-45.

Băltescu, C.A. 2016. Graduates' willingness to build a career in tourism. a view point of the students in the Tourism Profile Academic Programmes from the Transilvania University of Brasov. Annals, (3): 36-39.

Bezuidenhout, R. and Cronje, F. 2014. Research matters. Juta: Cape Town.

Bowker, L. and Villamizar, C. 2017. Embedding a records manager as a strategy for helping to positively influence an organization's records management culture. Records Management Journal, 27(1): 57-68.

Brown, K. and Malenfant, K.J. 2017. Academic library impact on student learning and success: findings from assessment in action team projects. Chicago: Association of College and Research Libraries.

Butler-Adam, J. 2018. The Fourth Industrial Revolution and education. South African Journal of Science, 114(5/6). DOI:10.17159/sajs.2018/a0271.

Chen, G. and Klimoski, R.J. 2007. Training and development of human resources at work: is the state of our science strong? Human Resource Management Review, 17(2): 180-190. DOI:10.1016/j.hrmr.2007.03.004.

Clement, J.C. 2013. A case study in disruptive technology innovation and tourism: City Corridor and Charles. Journal of Tourism, 14(1): 63-77.

Coates, H. and Goedegebuure, L. 2012. Recasting the academic workforce: why the attractiveness of the academic profession needs to be increased and eight possible strategies for how to go about this from an Australian perspective. Higher Education, 64(6): 875-889. DOI:10.1007/s10734-012-9534-3.

Creswell, J.H. 2009. Research design: qualitative, quantitative and mixed methods approaches. Los Angeles: Sage.

Farrell, L. 2017. Workplace literacy in the Fourth Industrial Revolution: The Literacy 4.0 Project. Melbourne: The University of Melbourne.

Fisk, P. 2017. Education $4.0 \ldots$ the future of learning will be dramatically different, in school and throughout life. 24 January. [Online]. https://www.thegeniusworks.com/2017/01/future-education-young-everyone-taught-together/ (24 February 2019).

Folinsbee, S. 2009. Workplace literacy: ethical issues through the lens of experience. New Directions for Adult \& Continuing Education, 123: 33-42. DOI:10.1002/ace.341.

Frick, L. and Kapp, C. 2009. The professional developments of academics: in pursuit of scholarship. In Higher education in South Africa: A scholarly look behind the scenes. E. Bitzer, Ed. Stellenbosch: Sun Press. 255-282. DOI:10.18820/9781920338183/12.

Goedegebuure, L. and Schubert, R. 2017. Vocational education and the innovation agenda: Towards the creation of effective innovation eco-systems. In Visions for Australian Tertiary Education. R. James, S. French and P. Kelly, Eds. Melbourne: University of Melbourne. 111-122.

Gilbert, S. 2017. Information literacy skills in the workplace: examining early career advertising professionals. Journal of Business \& Finance Librarianship, 22(2): 111-134. DOI:10.1080/08963568.2016.1258938.

Howlett, G. and Waemusa, Z. 2019. 21st century learning skills and autonomy. Teaching English with Technology, 19(1): 72-85.

Hoyer, J. 2011. Information is social: information literacy in context. Reference Services Review, 39(1): 10-23. DOI:10.1108/00907321111108088.

Kirton, J. and Barham, L. 2005. Information literacy in the workplace. Australian Library Journal, 54(4), 365-376.

Limberg, L. and Sundin, O. 2006. Teaching information seeking: relating information literacy education to theories of information behaviour. Information Research, 12(1): Art. 280.

Lloyd, A. 2011. Trapped between a rock and a hard place: what counts as information literacy in the workplace and how is it conceptualized? Library Trends, 60(2): 277-296.

Mackey, T.P. and Jacobson, T.E. 2011. Reframing information literacy as a metaliteracy. College \& Research Libraries, 72(1): $62-78$.

Molopyane, J. and Fourie, I. 2015. A framework for workplace information literacy in academic contexts: Central University of Technology, Free State (South Africa) as case study. Library Hi Tech, 33(4): 562-583.

DOI:10.1108/LHT-02-2015-0013. 
Neerputh, S. 2014. Academic integration of libraries at Universities of Technology (UoTs) in South Africa. PhD thesis. Durban University of Technology. [Online]. http://ir.dut.ac.za/handle/10321/1154 (24 February 2019).

Ottonicar, S.L.C., Valentim, M.L.P. and Mosconi, E. 2018. A competitive intelligence model based on information literacy: organizational competitiveness in the context of the 4th Industrial Revolution. Journal of Intelligence Studies in Business, 8(3): 55-65.

Perez, K.V.P. and Trello, O.M. 2012. The digital competence as a cross-cutting axis of higher education teachers' pedagogical competences, in the European higher education area. Procedia - Social and Behavioral Sciences, 46: $1112-1116$.

Saayman, M. and Geldenhuys, S. 2003. An analysis of skills required for selected sectors of the tourism industry. SA Journal for Research in Sport, Physical Education and Recreation, 25(1): 83-95.

Shamim, S., Cang, S., Yu, H., and Li, Y. 2017. Examining the feasibilities of industry 4.0 for the hospitality sector with the lens of management practice. Energies, 10(4): Art. 499. DOI:10.3390/en10040499.

Shivoro, R.S., Shalyefu, R.K. and Kadhila, N. 2018. Perspectives on graduate employability attributes for management sciences graduates. South African Journal of Higher Education, 32(1): 216-232. DOI:10.20853/32-1-1578.

Shumaker, D. 2012. The embedded librarian: innovative strategies for taking knowledge where it's needed. Medford, N.J.: Information Today.

Somerville, M.M. and Nino, M. 2007. Collaborative co-design: a user-centric approach for advancement of organizational learning, performance measurement and metrics. The International Journal for Library and Information Services, 8(3): 180-188.

South Africa: Department of Statistics. n.d. Tourism: jobs, the economy and spending. [Online]. http://www.statssa.gov.za/?p=9264 (17 December 2019).

Travis, T. 2011. From the classroom to the boardroom: The impact of information literacy instruction on workplace research skills. Education Libraries, 34(2): 19-31.

UNESCO. 2015. Higher education and the Sustainable Development Goals. [Online]. https://en.unesco.org/themes/higher-education/sdgs (1 March 2019).

Yiu. M. and Law, R. 2012. A review of hospitality internship: different perspectives of students, employers, and educators. Journal of Teaching in Travel \& Tourism, 12(4): 377-402. DOI:10.1080/15313220.2012.729459.

Zwane, F.N., Du Plessis, L. and Slabbert, E. 2014. Analysing the skills expectations of employers in the South African tourism industry. SA Journal of Human Resource Management, 12(1): Art. 550. DOI:10.4102/sajhrm.v12i1.550. 